\title{
Article \\ Cross-Sectional and Longitudinal Associations between Non-School Time Physical Activity, Sedentary Time, and Adiposity among Boys and Girls: An Isotemporal Substitution Approach
}

\author{
Kelsey L. McAlister ${ }^{1}\left(\mathbb{D}\right.$, Jennifer Zink $^{1}$, Daniel Chu ${ }^{1}$, Britni R. Belcher ${ }^{1, *(\mathbb{D})}$ and Genevieve F. Dunton ${ }^{1,2}$ \\ 1 Department of Preventive Medicine, University of Southern California, Los Angeles, CA 90032, USA; \\ kmcalist@usc.edu (K.L.M.); jennifaz@usc.edu (J.Z.); chudanie@usc.edu (D.C.); dunton@usc.edu (G.F.D.) \\ 2 Department of Psychology, University of Southern California, Los Angeles, CA 90032, USA \\ * Correspondence: bbelcher@usc.edu
}

check for updates

Citation: McAlister, K.L.; Zink, J.; Chu, D.; Belcher, B.R.; Dunton, G.F. Cross-Sectional and Longitudinal Associations between Non-School Time Physical Activity, Sedentary Time, and Adiposity among Boys and Girls: An Isotemporal Substitution Approach. Int. J. Environ. Res. Public Health 2021, 18, 4671. https:// doi.org/10.3390/ijerph18094671

Academic Editors: Michael J. Duncan, Cain Clark, Clarice Maria De Lucena Martins and Jorge Mota

Received: 27 March 2021

Accepted: 25 April 2021

Published: 27 April 2021

Publisher's Note: MDPI stays neutral with regard to jurisdictional claims in published maps and institutional affiliations.

Copyright: (c) 2021 by the authors. Licensee MDPI, Basel, Switzerland. This article is an open access article distributed under the terms and conditions of the Creative Commons Attribution (CC BY) license (https:// creativecommons.org/licenses/by/ $4.0 /)$.
Abstract: This study investigated the cross-sectional and longitudinal associations of the substitution of non-school time light physical activity (LPA), moderate-to-vigorous physical activity (MVPA), and sedentary time (ST) with adiposity in boys and girls. Boys $(n=65$, baseline Mage $=9.93 \pm 0.86$ years) and girls ( $n=77$, baseline Mage $=10.17 \pm 0.95$ years) wore waist-worn accelerometers (ActiGraph GT3X) at baseline and at a 30-month follow-up, from which non-school time LPA, MVPA, ST, and total device wear were quantified. Body mass index (BMI) and waist-toheight-ratio (WHR) were measured at baseline and follow-up. Body fat percent (BF\%) was obtained at follow-up only. Isotemporal substitution models assessed the cross-sectional and longitudinal associations of reallocating non-school time activity with BMI, WHR and BF\%. In boys, replacing $30 \mathrm{~min} /$ day of LPA with MVPA was cross-sectionally $(\beta=-8.26, p<0.05)$ associated with a lower $\mathrm{BF} \%$. Replacing $30 \mathrm{~min} /$ day of ST with MVPA was cross-sectionally $(\beta=-6.02, p<0.05)$ associated with a lower $\mathrm{BF} \%$ in boys. Longitudinally in boys, replacing $30 \mathrm{~min}$ of change in LPA with MVPA $(\beta=-7.42, p<0.10)$ and replacing 30 min of change in MVPA with ST $(\beta=5.78, p<0.10)$ over 30 months was marginally associated with less BF\%. Associations were null in girls $(p>0.05)$. These results may support targeting activity reallocation during non-school time for the purposes of adiposity improvement in boys. A multi-behavioral approach may be more appropriate for girls, as non-school time activity may not be driving adiposity status.

Keywords: reallocation; obesity; youth; sex differences; accelerometry

\section{Introduction}

One of the highest prevalence rates of obesity in the United States is among youth aged 6-11 years [1]. Youth with overweight or obesity have a 6-fold greater risk of having overweight or obesity as an adult, compared to their healthy weight counterparts [2], a finding that is supported by several tracking studies [3-6]. Unhealthy adiposity during childhood, such as excess weight and high total body fat, predisposes youth to adverse health outcomes as adults, including dyslipidemia, insulin resistance, hypertension, metabolic syndrome and inflammation [2,7]. Furthermore, studies among youth suggest that excess body fat around the waist, specifically, is associated with poor health outcomes and can uniquely contribute to hypertension, hyperlipidemia, insulin resistance, and overall cardiometabolic risk $[8,9]$.

Due to the well-documented health consequences associated with obesity during childhood, understanding the contributions of modifiable behaviors, such as physical activity (PA) and sedentary time (ST), to adiposity has been of interest. Moderate-tovigorous PA (MVPA) is consistently and inversely associated with adiposity markers such as waist circumference, body mass index (BMI), and total body fat in youth $[10,11]$. 
Evidence also demonstrates that light PA (LPA) is inversely associated with body fat, skinfold thickness, and BMI in youth [12]. However, the associations between ST and various adiposity markers have been inconsistent $[11,13]$. Many of these associations between ST and adiposity are attenuated when adjusting for MVPA [13,14], making it unclear how the combination of behaviors influence adiposity.

Since the amount of time within the day is finite, time spent on one activity displaces time spent in another. Isotemporal substitution is a statistical approach that mathematically estimates the associations of reallocating one type of activity with another of equal time [15]. Results of isotemporal substitution models yield estimated associations of activity reallocation, which may be easier for practitioners to understand and implement. Studies utilizing isotemporal substitution have found associations between the reallocation of activity and various adiposity markers in youth when analyzing activity across the entire day [16-19]. However, evidence suggests that youth participate in low levels of PA during school [20-22], possibly because youth do not necessarily have volitional control over activity during structured school-time. Additional evidence supports that youth do not compensate for lack of school-time PA outside of school [23,24], indicating that this may be a crucial time of day to target interventions. The effects of reallocating time spent sedentary to LPA and MVPA on adiposity has yet to be studied during time outside of school, which is when youth may have less structure and more autonomy over their health behaviors. An additional limitation of many previous studies is that they failed to account for the differences in body fat accumulation and distribution between boys and girls $[25,26]$, thus limiting our understanding of whether or not findings are generalizable to both sexes or are sex-specific. Understanding sex-specific associations could provide insight into tailored intervention strategies aimed at increasing PA and decreasing adiposity, particularly during the adolescent transition, which has sex-specific developmental milestones [27]. Given the developmental differences observed in boys and girls around this age $[25,26]$, we performed exploratory analyses with the purpose of describing cross-sectional and longitudinal associations of substituting non-school time (i.e., time outside of school-time) ST, LPA, and MVPA on adiposity in boys and girls.

\section{Materials and Methods}

\subsection{Study Design, Recruitment, and Participants}

Data were obtained from the Mother's and Their Children's Health (MATCH) Study, a longitudinal study examining stress, parenting factors, health behaviors, and obesity in mother and child dyads. A convenience sample was obtained between August 2014 and March 2016. Children ages 8-12 years were recruited from public elementary schools and after-school programs in the greater Los Angeles area. Children were recruited via informational flyers and in-person recruitment events. Families were included in the study if (1) the child was in third-sixth grade at study enrollment; (2) $\geq 50 \%$ of the child's custody was with the mother; and (3) the child was able to read English. Families were excluded from the study if (1) the child was currently taking medications for thyroid function or psychological conditions; (2) the child had health issues that limited PA participation; (3) the child was enrolled in special education programs; (4) the mother was pregnant; (5) the child was using oral or inhalant corticosteroids for asthma; (6) the child was classified as underweight by a BMI percentile $<5 \%$ (adjusted for sex and age); and/or (7) the mother was working more than two weekday evenings (between the hours of 5-9 p.m.) per week or more than $8 \mathrm{~h}$ on any weekend day.

\subsection{Procedures}

A detailed description of study procedures is reported elsewhere [28]. Briefly, parental consent and written child assent were obtained from each participant. Six waves of data collection were conducted at approximately 6-month intervals. Analyses for the present study included data from Wave 1 (baseline) and Wave 6 (+30 months). Children attended a 90 min, in-person data collection visit at each wave, either at a local school or community center. 
During the in-person visits, the participants completed paper-and-pencil questionnaires, underwent anthropometric measurements, and were given a waist-worn accelerometer to wear for seven consecutive days. Total body fat percent $(\mathrm{BF} \%)$ was obtained only during the last wave (30 months). Children were compensated USD 100 for completing procedures at each wave. The Institutional Review Board at the University of Southern California approved of the study.

\subsection{Measures}

\subsubsection{Demographic and Participant Characteristics}

Each mother completed questionnaires to report their highest level of education achieved (college degree or higher: yes vs. no) and their child's race/ethnicity (Hispanic: yes vs. no); children self-reported their date of birth and sex. Age in years was calculated based on the time between date of birth and the date of their baseline and 30-month visit. These covariates were selected due to their evidence of confounding activity-adiposity associations [29,30].

\subsubsection{Adiposity Markers}

Height was measured to the nearest 0.1 centimeter $(\mathrm{cm})$ and weight to the nearest 0.1 kilogram $(\mathrm{kg})$ using a professional stadiometer (Seca 213 Portable Stadiometer) and an electronically calibrated digital scale (Tanita WB-110A), respectively. Height and weight were measured in duplicate, with the average used in analyses. From these measurements, BMI $\left(\mathrm{kg} / \mathrm{m}^{2}\right)$ at baseline and 30 months were calculated. Waist circumference was measured using a standard tape measure and following the National Health and Nutrition Examination Survey (NHANES) protocol [31]. Waist circumference was measured at the superior iliac crest at the end of expiration to the nearest $0.1 \mathrm{~cm}$ and was measured in duplicate. A third measure was taken if the measures did not fall within $1 \mathrm{~cm}$. The average of all waist circumference measurements was used in the analyses [31]. Waist-to-height ratio (WHR) was computed for each child at baseline and at 30 months. At the 30-month follow-up, a bioelectrical impedance analysis scale (Tanita WB-110A) was used to obtain $\mathrm{BF} \%$ in each child participant, which has been previously validated for use in youth [32,33].

\subsubsection{Objective Non-School Time Physical Activity and Sedentary Time}

Participants were instructed to wear a waist-worn triaxial ActiGraph GT3X accelerometer (Penscacola, FL, USA) during all waking hours except for bathing and swimming for seven consecutive days. Data were collected in $30 \mathrm{~s}$ epochs. Similar to national studies in youth, periods of non-wear were considered $>60$ continuous minutes of zero counts [34-36]. School hours (8:00 a.m. to 3:00 p.m. during Monday-Friday) were removed from the accelerometer data prior to the calculation of all day-level summaries. Thus, non-school time activity was considered as any activity that occurred prior to 8:00 a.m. and after 3:00 p.m. on all weekdays and any activity on weekend days. As BF\% was only collected at 30 months, all cross-sectional analyses were conducted with follow-up data only. For cross-sectional analyses, non-school time wear compliance was defined as $\geq 4 \mathrm{~h}$ /day of wear during designated non-school time (i.e., hours before 8:00 a.m. and after 3:00 p.m.) on weekdays and $\geq 10 \mathrm{~h} /$ day of wear on weekend days for one or more days at the follow-up. For longitudinal analyses, valid non-school time wear compliance included wearing the accelerometer for one or more days at both the baseline and follow-up. Although the use of one or more valid days may be considered a liberal protocol, it aided in maximizing the sample size and ensured the inclusion of youth of various adiposity statuses, since previous evidence in youth suggests that a stricter valid number of days criteria excludes youth with overweight or obesity [37]. Another study in youth has also used this protocol [38], and a majority of youth included in the analytic sample had four or more valid accelerometer days (crosssectional analyses: $n=109$ at follow-up; longitudinal analyses: $n=121$ at baseline and $n=103$ at follow-up). Cut-points for time spent in LPA, MVPA, and ST were derived using age-specific thresholds for youth (adjusted for 30 s epochs) using the Freedson prediction 
equation equivalent to 4 metabolic equivalents (METs), which were consistent with national studies [34,39]. ST was defined as <100 activity counts per minute [40]. Non-school time mean LPA, MVPA, ST, and accelerometer wear-time in minutes per day were calculated for each participant and used in the analyses.

\subsection{Statistical Analysis}

All analyses were performed in SAS version 9.4 (SAS Institute Inc., Cary, NC, USA). Due to sex differences in the development of adipose mass, accumulation, and distribution [27], analyses were stratified by sex. Descriptive statistics, including the mean and standard deviation for continuous variables and frequency and the percent of categorical variables, were calculated for the analytic sample. Independent sample t-tests and chi-square tests were used to determine significant differences in continuous and categorical demographic, adiposity, and activity characteristics between those included and excluded in the analyses, respectively. Paired sample t-tests and independent samples $\mathrm{t}$-tests were used to test the differences in continuous demographic, adiposity, and activity characteristics between baseline and 30-month follow-up and between boys and girls, respectively. Chi-square analyses were used to test the differences between categorical participant demographic variables between boys and girls.

Linear regression models using isotemporal substitution [15] were used to identify the cross-sectional and longitudinal associations of replacing one type of non-school time activity (LPA, MVPA, ST) with another on BMI, WHR, and BF\% in boys and girls. Since sleep data were not collected, the resulting estimates were constrained to waking non-school time (waking time before 8:00 a.m. and after 3:00 p.m. on weekdays and any waking time on weekends). Mean non-school time LPA, MVPA, ST, and total accelerometer wear-time (LPA + MVPA + ST = total wear-time) in minutes per day were divided by a constant of 30 , similar to other studies using isotemporal substitution analyses [19,41]. Dividing by 30 allowed for estimates to be interpreted so that a one unit increase in each non-school time activity was representative of an increase of $30 \mathrm{~min} /$ day. Additionally, we ran ancillary analyses using 15 min substitutions (see Supplementary Table S1a,b). Due to the structure of the isotemporal substitution models, the $p$-values for the 15 min reallocation models are equivalent to the 30 min models; however, the beta estimates represent the associations for a smaller amount of activity replacement. In each isotemporal substitution model, the activity of interest (the one being replaced) was removed from the model (e.g., ST), with all other activities (e.g., LPA and MVPA), total wear-time, and other covariates remaining. By removing the activity of interest, the total wear-time then represents the estimate of the activity removed while also acting as a covariate. The corresponding coefficients represent the association of replacing the activity removed with the other activity, while keeping all other variables constant [15]. Cross-sectional models were adjusted for total wear-time and the a priori covariates mentioned above $[15,29,30]$.

Longitudinal isotemporal substitution models were fit such that estimates reflected the association of replacing the change from baseline to 30 months in non-school time activity on BMI, WHR, and $\mathrm{BF} \%$ at the 30-month follow-up. The mean change in minutes per day for non-school time LPA, MVPA, and ST from baseline to 30 months (i.e., activity at follow-up-activity at baseline = change in activity) was calculated. The mean change for non-school time LPA, MVPA, and ST were each divided by a constant of 30 to capture the associations of replacing a $30 \mathrm{~min}$ change from baseline to follow-up of one activity with a $30 \mathrm{~min}$ change of another. For example, the models that removed the ST estimated the associations between replacing a 30 min change of ST over 30 months with a 30 min change in LPA and MVPA and each adiposity measure at the 30-month follow-up. Similar to cross-sectional models, additional longitudinal isotemporal substitution models estimating the associations between 15 min activity substitutions and adiposity were conducted (see Supplementary Table S1c,d). Longitudinal models were adjusted for a priori covariates $[29,30]$ and additionally adjusted for activity levels and accelerometer wear-time at baseline. In order to satisfy the model assumption of homoscedasticity, log BMI was used 
in cross-sectional and longitudinal models. Linearity and homoscedasticity assumptions were met in cross-sectional and longitudinal models with WHR and BF\%. Bivariate Pearson correlations were used to check for collinearity between the activity variables used in the models. Significance was set at $p<0.05$, and marginal significance was set at $p<0.10$. Cohen's $\mathrm{f}^{2}$ effect size was calculated. G*Power version 3.1 was used to conduct post hoc sample size estimations and power analyses [42].

\section{Results}

\subsection{Data Availability and Characteristics of Analytic Sample}

A total of 202 children were enrolled in the MATCH Study. For cross-sectional analyses, 152 children completed the study procedures at 30 months, of which 143 provided at least one valid day of accelerometer wear. Of the 143 participants, one was missing ethnicity and mother's highest level of education, and 12 were missing BF\%. These exclusions yielded an analytic sample of 142 for models with BMI and WHR and 130 for models with $\mathrm{BF} \%$ for cross-sectional analyses. Longitudinally, 134 children had at least one valid day of accelerometer wear at baseline and 30 months and were included in models. Independent samples t-tests and chi-square analyses showed no differences in child age, sex, ethnicity, mother's highest level of education, BMI, and WHR at baseline between those included vs. excluded from the analyses $(n=130-142$ participants included vs. $n=60-72$ participants excluded in cross-sectional models, $n=122-134$ participants included vs. $n=68-80$ participants excluded in the longitudinal models; all $p$ 's $>0.10$ ).

Table 1 presents demographic and non-school time activity characteristics in the analytic sample at baseline, 30 months, and the change across 30 months by sex. Of the 142 children, $45.78 \%(65 / 142)$ were boys and $54.23 \%(77 / 142)$ were girls. The mean (SD) BMI for boys was $18.98 \mathrm{~kg} / \mathrm{m}^{2}(4.01)$ at baseline and $20.69 \mathrm{~kg} / \mathrm{m}^{2}(4.86) 30$ months later. Similarly, girls had a mean (SD) BMI of $19.00 \mathrm{~kg} / \mathrm{m}^{2}(4.01)$ at baseline and $21.44 \mathrm{~kg} / \mathrm{m}^{2}$ (4.85) at follow-up. The mean (SD) BF\% for boys was $16.86 \%(10.04)$, which was significantly lower $(p<0.01)$ than the mean (SD) BF\% girls, which was $24.14 \%$ (10.10). Boys also accumulated more mean daily minutes of MVPA compared to girls at baseline and follow-up (both $p^{\prime}$ s < 0.01). Boys and girls both had significant increases in BMI and decreases in LPA and MVPA from baseline to 30 months (all $p^{\prime}$ s < 0.01). Girls, but not boys, additionally had a significant increase in ST across the 30 months $(p<0.01)$.

Table 1. Participant characteristics for the analytic sample ( $n=142$; boys $n=65$; girls $n=77$ ).

\begin{tabular}{|c|c|c|c|c|c|c|}
\hline & \multicolumn{3}{|c|}{ Boys } & \multicolumn{3}{|c|}{ Girls } \\
\hline & Baseline $^{a}$ & $\begin{array}{l}\text { 30-Month } \\
\text { Follow-Up }\end{array}$ & $\begin{array}{l}\text { Change from } \\
\text { Baseline to } \\
\text { Follow-Up }\end{array}$ & Baseline $^{\mathrm{d}}$ & $\begin{array}{l}\text { 30-Month } \\
\text { Follow-Up }\end{array}$ & $\begin{array}{l}\text { Change from } \\
\text { Baseline to } \\
\text { Follow-Up e }\end{array}$ \\
\hline & Mean \pm SD & Mean \pm SD & Mean \pm SD & Mean \pm SD & Mean \pm SD & Mean \pm SD \\
\hline Age (years) & $9.93 \pm 0.86$ & $12.40 \pm 0.91$ & $2.43 \pm 0.19^{* *}$ & $10.17 \pm 0.95$ & $12.57 \pm 0.94$ & $2.38 \pm 0.19 * *$ \\
\hline $\mathrm{BMI}\left(\mathrm{kg} / \mathrm{m}^{2}\right)$ & $18.98 \pm 4.01$ & $20.69 \pm 4.86$ & $1.85 \pm 1.82 * *$ & $19.00 \pm 4.01$ & $21.44 \pm 4.85$ & $2.24 \pm 1.84 * *$ \\
\hline WHR & $0.49 \pm 0.06$ & $0.49 \pm 0.06$ & $-0.001 \pm 0.04^{b}$ & $0.50 \pm 0.07$ & $0.51 \pm 0.06$ & $0.06 \pm 0.05^{\mathrm{e}}$ \\
\hline $\mathrm{BF} \%(\%)$ & - & $16.86 \pm 10.04^{\mathrm{c} \wedge}$ & - & - & $24.14 \pm 10.10^{\mathrm{d} \wedge}$ & - \\
\hline LPA (min/day) & $157.21 \pm 34.29$ & $134.06 \pm 45.13$ & $-22.04 \pm 54.48^{* *}$ & $166.25 \pm 38.66$ & $132.81 \pm 50.77$ & $-30.72 \pm 44.51 * *$ \\
\hline MVPA (min/day) & $36.25 \pm 19.67^{\wedge}$ & $21.27 \pm 16.26^{\wedge}$ & $-13.62 \pm 19.64^{* *}$ & $27.50 \pm 17.40^{\wedge}$ & $15.17 \pm 11.93^{\wedge}$ & $-11.39 \pm 18.99^{* *}$ \\
\hline ST (min/day) & $298.28 \pm 72.70$ & $305.39 \pm 77.66$ & $6.07 \pm 105.45$ & $281.12 \pm 67.18$ & $321.36 \pm 72.78$ & $34.66 \pm 89.00 * *$ \\
\hline $\begin{array}{l}\text { Total wear-time } \\
\text { (min/day) }\end{array}$ & $491.74 \pm 90.63$ & $460.72 \pm 97.29$ & $-29.59 \pm 139.82$ & $474.87 \pm 77.79$ & $469.34 \pm 89.36$ & $-7.45 \pm 100.48$ \\
\hline
\end{tabular}


Table 1. Cont.

\begin{tabular}{|c|c|c|c|c|c|c|}
\hline & \multicolumn{3}{|c|}{ Boys } & \multicolumn{3}{|c|}{ Girls } \\
\hline & Baseline $^{a}$ & $\begin{array}{l}\text { 30-Month } \\
\text { Follow-Up }\end{array}$ & $\begin{array}{l}\text { Change from } \\
\text { Baseline to } \\
\text { Follow-Up }\end{array}$ & Baseline $^{\mathrm{d}}$ & $\begin{array}{l}\text { 30-Month } \\
\text { Follow-Up }\end{array}$ & $\begin{array}{c}\text { Change from } \\
\text { Baseline to } \\
\text { Follow-Up }\end{array}$ \\
\hline & Mean \pm SD & Mean \pm SD & Mean \pm SD & Mean \pm SD & Mean \pm SD & Mean \pm SD \\
\hline & $n(\%)$ & $n(\%)$ & & $n(\%)$ & $n(\%)$ & \\
\hline \multicolumn{7}{|l|}{ Ethnicity } \\
\hline Hispanic & $28(44.44)$ & $32(49.23)$ & - & $44(60.27)$ & $36(46.75)$ & - \\
\hline Non-Hispanic & $35(55.56)$ & $33(50.77)$ & - & $29(39.73)$ & $41(53.25)$ & - \\
\hline \multicolumn{7}{|l|}{$\begin{array}{c}\text { Mother's } \\
\text { education level }\end{array}$} \\
\hline $\begin{array}{l}\text { Less than a } \\
\text { college degree }\end{array}$ & $29(46.03)$ & $30(40.15)$ & - & $25(34.25)$ & $30(38.96)$ & - \\
\hline $\begin{array}{c}\text { College degree } \\
\text { and above }\end{array}$ & $34(53.97)$ & $35(53.85)$ & - & $48(65.75)$ & $47(61.04)$ & - \\
\hline
\end{tabular}

Abbreviations and acronyms-SD: standard deviation; min: minutes; \%: percent; BMI: body mass index; WHR: waist-to-height ratio; BF\%: body fat percent; LPA: light physical activity; MVPA: moderate-to-vigorous physical activity; ST: sedentary time. ${ }^{\mathrm{a}} n=63 ;{ }^{\mathrm{b}} n=62$; ${ }^{\mathrm{c}} n=59 ;{ }^{\mathrm{d}} n=71 ;{ }^{\mathrm{e}} n=68 ;{ }^{* *}$ statistically significant difference between baseline and follow-up at $p<0.01$. ^ statistically significant difference between mean in boys vs. mean in girls at $p<0.01$.

\subsection{Cross-Sectional Associations of Replacing Time in LPA, MVPA, and ST with Adiposity}

Tables 2 and 3 show cross-sectional associations of replacing 30 min of each nonschool time activity for one another on BMI, WHR, and BF\% in boys and girls. In boys, replacing $30 \mathrm{~min} /$ day of LPA with $30 \mathrm{~min}$ of MVPA was marginally associated with lower BMI $(\beta=-0.13,95 \%$ CI $-0.27,0.01, p \leq 0.10)$, lower WHR $(\beta=-0.04,95 \%$ CI $-0.08,0.01$, $p \leq 0.10)$, and significantly associated with less $\mathrm{BF} \%(\beta=-8.26,95 \% \mathrm{CI}-15.42,-1.09$, $p<0.05$ ). In boys, replacing $30 \mathrm{~min} /$ day of MVPA with $30 \mathrm{~min}$ of ST was significantly associated with more $\mathrm{BF} \%(\beta=6.02,95 \% \mathrm{CI} 0.49,11.55, p<0.05)$. Given the structure of the isotemporal substitution, the estimates were inversed when replacing MVPA with LPA, ST with LPA, and ST with MVPA with the same $p$-value (see Tables 2 and 3). All other associations in boys were null (all $p^{\prime} \mathrm{s}>0.10$ ). In girls, replacing $30 \mathrm{~min} /$ day of LPA with MVPA or ST was not cross-sectionally related to BMI, WHR, or BF\% (all $p^{\prime}$ s $>0.10$ ). Post hoc sample size calculations showed that 62 participants were needed to achieve a power of 0.8 and a medium effect size (Cohen's $\mathrm{f}^{2}$ ) of 0.25 . The cross-sectional isotemporal substitution models yielded a Cohen's $\mathrm{f}^{2}$, an indicator of effect size, of $0.20-0.40$ and post hoc power analyses indicated that models yielded a power of 0.85-0.99.

Table 2. Cross-sectional replacement effects $(\beta[95 \% \mathrm{CI}])$ at the follow-up of substituting 30 min of non-school time LPA, MVPA, and ST on BMI, WHR, and BF\% in boys $(n=65)$.

\section{BMI $^{\text {a }}$}

With $30 \mathrm{~min} /$ day of:

\begin{tabular}{|c|c|c|c|c|}
\hline Replacing $30 \mathrm{~min} /$ day of: & LPA & MVPA & ST & $\begin{array}{c}\text { Total } \\
\text { wear-time }\end{array}$ \\
\hline LPA & - & $\begin{array}{c}-0.13 \\
{[-0.27,0.01]^{\#}}\end{array}$ & $\begin{array}{c}-0.05 \\
{[-0.10,0.003]^{\#}}\end{array}$ & $\begin{array}{c}0.04 \\
{[-0.005,0.08]^{\#}}\end{array}$ \\
\hline MVPA & $\begin{array}{c}0.13 \\
{[-0.01,0.27]^{\#}}\end{array}$ & - & $\begin{array}{c}0.08 \\
{[-0.03,0.19]}\end{array}$ & $\begin{array}{c}-0.10 \\
{[-0.21,0.02]}\end{array}$ \\
\hline ST & $\begin{array}{c}0.05 \\
{[-0.003,0.10]^{\#}}\end{array}$ & $\begin{array}{c}-0.08 \\
{[-0.19,0.03]}\end{array}$ & - & $\begin{array}{c}-0.01 \\
{[-0.03,0.01]}\end{array}$ \\
\hline
\end{tabular}


Table 2. Cont.

\begin{tabular}{|c|c|c|c|c|}
\hline \multicolumn{5}{|c|}{ WHR } \\
\hline \multicolumn{5}{|c|}{ With 30 min/day of: } \\
\hline Replacing $30 \mathrm{~min} /$ day of: & LPA & MVPA & ST & $\begin{array}{c}\text { Total } \\
\text { wear-time }\end{array}$ \\
\hline LPA & - & $\begin{array}{c}-0.04 \\
{[-0.08,0.01]^{\#}}\end{array}$ & $\begin{array}{c}-0.01 \\
{[-0.03,0.01]^{\#}}\end{array}$ & $\begin{array}{c}0.01 \\
{[-0.01,0.02]}\end{array}$ \\
\hline MVPA & $\begin{array}{c}0.04 \\
{[-0.01,0.08]^{\#}}\end{array}$ & - & $\begin{array}{c}0.03 \\
{[-0.01,0.06]}\end{array}$ & $\begin{array}{c}-0.03 \\
{[-0.06,0.01]}\end{array}$ \\
\hline ST & $\begin{array}{c}0.01 \\
{[-0.01,0.03]^{\#}}\end{array}$ & $\begin{array}{c}-0.03 \\
{[-0.06,0.01]}\end{array}$ & - & $\begin{array}{c}-0.002 \\
{[-0.01,0.004]}\end{array}$ \\
\hline \multicolumn{5}{|c|}{$\mathrm{BF} \% \mathrm{~b}$} \\
\hline \multicolumn{5}{|c|}{ With 30 min/day of: } \\
\hline Replacing $30 \mathrm{~min} /$ day of: & LPA & MVPA & ST & $\begin{array}{c}\text { Total } \\
\text { wear-time }\end{array}$ \\
\hline LPA & - & $\begin{array}{c}-8.26 \\
{[-15.42,-1.09] *}\end{array}$ & $\begin{array}{c}-2.24 \\
{[-4.85,0.38]^{\#}}\end{array}$ & $\begin{array}{c}1.72 \\
{[-0.46,3.89]}\end{array}$ \\
\hline MVPA & $\begin{array}{c}8.26 \\
{[1.09,15.42] *}\end{array}$ & - & $\begin{array}{c}6.02 \\
{[0.49,11.55] *}\end{array}$ & $\begin{array}{c}-6.54 \\
{[-12.29,-0.79] *}\end{array}$ \\
\hline ST & $\begin{array}{c}2.24 \\
{[-0.38,4.85]}\end{array}$ & $\begin{array}{c}-6.02 \\
{[-11.55,0.49]}\end{array}$ & - & $\begin{array}{c}-0.52 \\
{[-1.56,0.52]}\end{array}$ \\
\hline
\end{tabular}

Bold estimates represent significant or marginally significant associations. Abbreviations—min: minutes; CI: confidence interval; LPA: light physical activity; MVPA: moderate-to-vigorous physical activity; ST: sedentary time; BMI: body mass index; WHR: waist-to-height ratio; BF\%: body fat percent. All models were adjusted for child age, ethnicity, mother's education, and accelerometer wear-time. ${ }^{a}$ Log BMI was used to satisfy model assumptions. Estimates are presented in the $\log$ transformation of BMI. ${ }^{\mathrm{b}} n=59{ }^{*} p<0.05,{ }^{\#} p<0.10$.

Table 3. Cross-sectional replacement effects $(\beta[95 \% \mathrm{CI}])$ at follow-up of substituting $30 \mathrm{~min}$ of non-school time LPA, MVPA, and ST on BMI, WHR, and BF\% in girls $(n=77)$.

\section{BMI $^{\text {a }}$}

With $30 \mathrm{~min} /$ day of:

\begin{tabular}{|c|c|c|c|c|}
\hline Replacing $30 \mathrm{~min} /$ day of: & LPA & MVPA & ST & $\begin{array}{c}\text { Total } \\
\text { wear-time }\end{array}$ \\
\hline LPA & - & $\begin{array}{c}0.02 \\
{[-0.13,0.17]}\end{array}$ & $\begin{array}{c}0.03 \\
{[-0.01,0.07]}\end{array}$ & $\begin{array}{c}0.003 \\
{[-0.03,0.03]}\end{array}$ \\
\hline MVPA & $\begin{array}{c}-0.02 \\
{[-0.17,0.13]}\end{array}$ & - & $\begin{array}{c}0.01 \\
{[-0.12,0.13]}\end{array}$ & $\begin{array}{c}0.03 \\
{[-0.11,0.16]}\end{array}$ \\
\hline ST & $\begin{array}{c}-0.03 \\
{[-0.07,0.01]}\end{array}$ & $\begin{array}{c}-0.01 \\
{[-0.13,0.12]}\end{array}$ & - & $\begin{array}{c}0.03 \\
{[0.01,0.05]}\end{array}$ ** \\
\hline \multicolumn{5}{|c|}{ WHR } \\
\hline \multicolumn{5}{|c|}{ With 30 min/day of: } \\
\hline Replacing $30 \mathrm{~min} /$ day of: & LPA & MVPA & ST & $\begin{array}{c}\text { Total } \\
\text { wear-time }\end{array}$ \\
\hline LPA & - & $\begin{array}{c}-0.004 \\
{[-0.05,0.04]}\end{array}$ & $\begin{array}{c}0.01 \\
{[-0.01,0.02]}\end{array}$ & $\begin{array}{c}0.002 \\
{[-0.01,0.01]}\end{array}$ \\
\hline MVPA & $\begin{array}{c}0.004 \\
{[-0.04,0.05]}\end{array}$ & - & $\begin{array}{c}0.01 \\
{[-0.03,0.05]}\end{array}$ & $\begin{array}{c}-0.003 \\
{[-0.04,0.04]}\end{array}$ \\
\hline ST & $\begin{array}{c}-0.01 \\
{[-0.02,0.01]}\end{array}$ & $\begin{array}{c}-0.01 \\
{[-0.05,0.03]}\end{array}$ & - & $\begin{array}{c}0.01 \\
{[0.003,0.02] * *}\end{array}$ \\
\hline
\end{tabular}


Table 3. Cont.

\begin{tabular}{|c|c|c|c|c|}
\hline \multicolumn{5}{|c|}{$\mathrm{BF} \% \mathrm{~b}$} \\
\hline \multicolumn{5}{|c|}{ With 30 min/day of: } \\
\hline Replacing $30 \mathrm{~min} /$ day of: & LPA & MVPA & ST & $\begin{array}{c}\text { Total } \\
\text { wear-time }\end{array}$ \\
\hline LPA & - & $\begin{array}{c}-0.33 \\
{[-7.74,7.09]}\end{array}$ & $\begin{array}{c}1.45 \\
{[-0.72,3.62]}\end{array}$ & $\begin{array}{c}-0.014 \\
{[-1.60,1.57]}\end{array}$ \\
\hline MVPA & $\begin{array}{c}0.33 \\
{[-7.09,7.74]}\end{array}$ & - & $\begin{array}{c}1.78 \\
{[-4.44,7.99]}\end{array}$ & $\begin{array}{c}-0.34 \\
{[-7.02,6.34]}\end{array}$ \\
\hline ST & $\begin{array}{c}-1.45 \\
{[-3.62,0.72]}\end{array}$ & $\begin{array}{c}-1.78 \\
{[-7.99,4.44]}\end{array}$ & - & $\begin{array}{c}1.44 \\
{[0.31,2.57] \text { * }}\end{array}$ \\
\hline
\end{tabular}

Bold estimates represent significant or marginally significant associations. Abbreviations-min: minutes; CI: confidence interval; LPA: light physical activity; MVPA: moderate-to-vigorous physical activity; ST: sedentary time; BMI: body mass index; WHR: waistto-height ratio; $\mathrm{BF} \%$ : body fat percent. All models were adjusted for child age, ethnicity, mother's education, and accelerometer wear-time.

${ }^{\mathrm{a}} \log$ BMI was used to satisfy model assumptions. Estimates are presented in the $\log$ transformation of BMI. ${ }^{\mathrm{b}} n=71 ;{ }^{* *} p<0.01 ;{ }^{*} p<0.05$.

\subsection{Longitudinal Associations Replacing Time in LPA, MVPA and ST on Adiposity}

Tables 4 and 5 show longitudinal estimates for replacing a 30 min change of LPA, MVPA, and ST over 30 months on BMI, WHR, and BF\% at the 30-month follow-up. In boys, replacing a change of $30 \mathrm{~min}$ of LPA with a change of $30 \mathrm{~min}$ of MVPA over 30 months was marginally associated with less $\mathrm{BF} \%(\beta=-7.42,95 \% \mathrm{CI}-15.44,0.60, p \leq 0.10)$. Replacing a change of $30 \mathrm{~min}$ of MVPA with a change of $30 \mathrm{~min}$ of ST in boys was marginally associated with more BF\% ( $\beta=5.78,95 \% \mathrm{CI}-0.36,11.93, p \leq 0.10)$. Similar to the cross-sectional models, estimates were inversed when replacing MVPA with LPA and ST with MVPA (see Tables 4 and 5). All other longitudinal associations in boys were null (all $p^{\prime} \mathrm{s}>0.10$ ). All longitudinal associations in girls were null (all $p^{\prime} \mathrm{s}>0.10$ ). Post hoc sample size calculations indicated that 72 participants were needed to achieve a power of 0.8 and a medium effect size (Cohen's $\mathrm{f}^{2}$ ) of 0.25 . The longitudinal isotemporal substitution models yielded a Cohen's $\mathrm{f}^{2}$ of $0.33-0.54$ and a power of $0.81-0.98$.

Table 4. Isotemporal substitution associations ( $\beta[95 \% \mathrm{CI}])$ using $30 \mathrm{~min}$ reallocations between 30 -month changes in non-school time LPA, MVPA, and ST and BMI, WHR, and BF\% at 30-month follow-up in boys $(n=63)$.

BMI $^{\text {a }}$

\begin{tabular}{cccccc}
\hline & With $30 \mathrm{~min} /$ day of: & & & \\
\hline Replacing $30 \mathrm{~min} /$ day of: & LPA & MVPA & ST & $\begin{array}{c}\text { Total } \\
\text { wear-time }\end{array}$ \\
\hline LPA & - & -0.10 & -0.04 & 0.03 \\
{$[-0.02,0.07]$} & {$[-0.09,0.01]$} & 0.06 & -0.07 \\
MVPA & 0.10 & $-0.26,0.06]$ & {$[-0.07,0.18]$} & {$[-0.20,0.06]$} \\
\hline ST & {$[-0.06,0.26]$} & -0.04 & -0.06 & -0.01 & {$[-0.03,0.01]$} \\
\hline
\end{tabular}


Table 4. Cont.

\begin{tabular}{|c|c|c|c|c|}
\hline \multicolumn{5}{|c|}{ WHR } \\
\hline \multicolumn{5}{|c|}{ With 30 min/day of: } \\
\hline Replacing $30 \mathrm{~min} /$ day of: & LPA & MVPA & ST & $\begin{array}{c}\text { Total } \\
\text { wear-time }\end{array}$ \\
\hline LPA & - & $\begin{array}{c}-0.02 \\
{[-0.07,0.02]}\end{array}$ & $\begin{array}{c}-0.006 \\
{[-0.02,0.01]}\end{array}$ & $\begin{array}{c}0.004 \\
{[-0.009,0.02]}\end{array}$ \\
\hline MVPA & $\begin{array}{c}0.03 \\
{[-0.02,0.07]}\end{array}$ & - & $\begin{array}{c}0.02 \\
{[-0.02,0.06]}\end{array}$ & $\begin{array}{c}-0.02 \\
{[-0.06,0.02]}\end{array}$ \\
\hline ST & $\begin{array}{c}0.006 \\
{[-0.01,0.02]}\end{array}$ & $\begin{array}{c}-0.02 \\
{[-0.06,0.02]}\end{array}$ & - & $\begin{array}{c}-0.002 \\
{[-0.01,0.004]}\end{array}$ \\
\hline \multicolumn{5}{|c|}{$\mathrm{BF} \% \mathrm{~b}$} \\
\hline \multicolumn{5}{|c|}{ With 30 min/day of: } \\
\hline Replacing $30 \mathrm{~min} /$ day of: & LPA & MVPA & ST & $\begin{array}{c}\text { Total } \\
\text { wear-time }\end{array}$ \\
\hline LPA & - & $\begin{array}{c}-7.42 \\
{[-15.44,0.60]^{\#}}\end{array}$ & $\begin{array}{c}-1.64 \\
{[-4.37,1.10]}\end{array}$ & $\begin{array}{c}1.23 \\
{[-1.09,3.55]}\end{array}$ \\
\hline MVPA & $\begin{array}{c}7.42 \\
{[-0.60,15.44]}\end{array}$ & - & $\begin{array}{c}5.78 \\
{[-0.36,11.93]^{\#}}\end{array}$ & $\begin{array}{c}-6.19 \\
{[-12.55,0.18]^{\#}}\end{array}$ \\
\hline ST & $\begin{array}{c}1.64 \\
{[-1.10,4.37]}\end{array}$ & $\begin{array}{c}-5.78 \\
{[-11.93,0.36}\end{array}$ & - & $\begin{array}{c}-0.40 \\
{[-1.40,0.59]}\end{array}$ \\
\hline
\end{tabular}

Bold estimates represent significant or marginally significant associations. Abbreviations-min: minutes; CI: confidence interval; LPA: light physical activity; MVPA: moderate-to-vigorous physical activity; ST: sedentary time; BMI: body mass index; WHR: waist-to-height ratio; $\mathrm{BF} \%$ : body fat percent. All models adjusted for child age, ethnicity, mother's education, activity, and accelerometer wear-time at baseline. ${ }^{a}$ Log BMI was used to satisfy model assumptions. Estimates are presented in the log transformation of BMI. ${ }^{\mathrm{b}} n=57 .{ }^{\#} p<0.10$.

Table 5. Isotemporal substitution associations $(\beta[95 \% \mathrm{CI}])$ using $30 \mathrm{~min}$ reallocations between 30 -month changes in non-school time LPA, MVPA, and ST and BMI, WHR, and BF\% at 30-month follow-up in girls $(n=71)$.

BMI $^{\text {a }}$

With 30 min/day of:

\begin{tabular}{|c|c|c|c|c|}
\hline Replacing 30 min/day of: & LPA & MVPA & ST & $\begin{array}{c}\text { Total } \\
\text { wear-time }\end{array}$ \\
\hline LPA & - & $\begin{array}{c}0.03 \\
{[-0.13,0.19]}\end{array}$ & $\begin{array}{c}0.03 \\
{[-0.02,0.08]}\end{array}$ & $\begin{array}{c}-0.002 \\
{[-0.04,0.04]}\end{array}$ \\
\hline MVPA & $\begin{array}{c}-0.03 \\
{[-0.19,0.13]}\end{array}$ & - & $\begin{array}{c}0.002 \\
{[-0.14,0.14]}\end{array}$ & $\begin{array}{c}0.03 \\
{[-0.12,0.17]}\end{array}$ \\
\hline ST & $\begin{array}{c}-0.03 \\
{[-0.08,0.02]}\end{array}$ & $\begin{array}{c}-0.002 \\
{[-0.14,0.14]}\end{array}$ & - & $\begin{array}{c}0.03 \\
{[0.003,0.05] \text { * }}\end{array}$ \\
\hline \multicolumn{5}{|c|}{ WHR } \\
\hline \multicolumn{5}{|c|}{ With 30 min/day of: } \\
\hline Replacing 30 min/day of: & LPA & MVPA & ST & $\begin{array}{c}\text { Total } \\
\text { wear-time }\end{array}$ \\
\hline LPA & - & $\begin{array}{c}-0.01 \\
{[-0.05,0.04]}\end{array}$ & $\begin{array}{c}0.006 \\
{[-0.01,0.02]}\end{array}$ & $\begin{array}{c}0.002 \\
{[-0.01,0.01]}\end{array}$ \\
\hline MVPA & $\begin{array}{c}0.01 \\
{[-0.04,0.04]}\end{array}$ & - & $\begin{array}{c}0.01 \\
{[-0.03,0.05]}\end{array}$ & $\begin{array}{c}-0.003 \\
{[-0.05,0.04]}\end{array}$ \\
\hline ST & $\begin{array}{c}-0.006 \\
{[-0.02,0.01]}\end{array}$ & $\begin{array}{c}-0.01 \\
{[-0.05,0.03]}\end{array}$ & - & $\begin{array}{c}0.01 \\
{[0.001,0.02] \text { * }}\end{array}$ \\
\hline
\end{tabular}


Table 5. Cont.

\begin{tabular}{|c|c|c|c|c|}
\hline \multicolumn{5}{|c|}{ BF\% ${ }^{b}$} \\
\hline \multicolumn{5}{|c|}{ With 30 min/day of: } \\
\hline Replacing $30 \mathrm{~min} /$ day of: & LPA & MVPA & ST & $\begin{array}{c}\text { Total } \\
\text { wear-time }\end{array}$ \\
\hline LPA & - & $\begin{array}{c}0.42 \\
{[-7.30,8.14]}\end{array}$ & $\begin{array}{c}1.21 \\
{[-1.22,3.64]}\end{array}$ & $\begin{array}{c}-0.06 \\
{[-1.87,1.74]}\end{array}$ \\
\hline MVPA & $\begin{array}{c}-0.42 \\
{[-8.14,7.30]}\end{array}$ & - & $\begin{array}{c}0.79 \\
{[-5.68,7.25]}\end{array}$ & $\begin{array}{c}0.36 \\
{[-6.58,7.29]}\end{array}$ \\
\hline ST & $\begin{array}{c}-1.21 \\
{[-3.64,1.22]}\end{array}$ & $\begin{array}{c}-0.79 \\
{[-7.25,5.68]}\end{array}$ & - & $\begin{array}{c}1.14 \\
{[-0.10,2.39]}\end{array}$ \\
\hline
\end{tabular}

Bold estimates represent significant or marginally significant associations. Abbreviations-min: minutes; CI: confidence interval; LPA: light physical activity; MVPA: moderate-to-vigorous physical activity; ST: sedentary time; BMI: body mass index; WHR: waist-toheight ratio; $\mathrm{BF} \%$ : body fat percent. All models adjusted for child age, ethnicity, mother's education, activity, and accelerometer wear-time at baseline. ${ }^{\mathrm{a}}$ Log BMI was used to satisfy model assumptions. Estimates are presented in the log transformation of BMI. ${ }^{\mathrm{b}} n=65 .{ }^{*} p<0.05$, $\# p<0.10[43]$.

\section{Discussion}

This study used isotemporal substitution to identify whether replacing non-school time LPA, MVPA, and ST with equivalent time in each corresponding activity was crosssectionally and longitudinally associated with adiposity separately in boys and girls. Similar to other studies [44,45], boys and girls had significant decreases in non-school time LPA and MVPA from baseline to 30 months, and girls additionally had an increase in non-school time ST. Our main findings suggest that replacing $30 \mathrm{~min} /$ day in LPA with MVPA and replacing $30 \mathrm{~min} /$ day of ST with MVPA were cross-sectionally associated with decreases in $\mathrm{BF} \%$ in boys; however, these associations were marginal in longitudinal models. Favorable but marginal associations were observed for replacing $30 \mathrm{~min} /$ day of LPA with MVPA on BMI and WHR outcomes in boys cross-sectionally, but not longitudinally. Contrary to expected directions, replacing $30 \mathrm{~min} /$ day of LPA with ST was marginally related to lower BMI, WHR, and BF\% in boys in cross-sectional analyses. All cross-sectional and longitudinal replacement estimates were nonsignificant among girls.

To our knowledge, this is one of the first studies to find favorable cross-sectional associations between activity reallocation and body fatness in boys outside of schooltime and during puberty. Longitudinal results suggested that $30 \mathrm{~min}$ reallocations in change in activity over a 30-month period may benefit body fatness in boys at 30 months. Replacing $30 \mathrm{~min} /$ day of non-school time LPA or ST with MVPA could counteract agerelated reductions in MVPA [44,46] and could benefit BF\% in boys. Only one other study appears to have used isotemporal substitution among boys and girls separately, finding that replacing entire-day LPA or ST with MVPA was associated with lower fat mass indices in both sexes ages 9-11 years [41]. Similarly, Collings et al. found that substituting ST with light, moderate, or vigorous PA was inversely associated with fat and trunk fat indices in younger youth [47]. Other studies of activity levels across the entire day in youth aged 6-11 years suggested that reallocating ST to LPA and MVPA could improve multiple measures of body fatness $[17,18]$. However, while our findings are consistent with some prior studies, our models were marginally statistically significant.

An important distinction between our analyses and prior studies is that we only included non-school time activity. Youth may be more limited in their ability to modify movement behaviors during designated school-time, presenting challenges for activity reallocation recommendations. Although school-based interventions have been successful in increasing school-time PA participation [48], evidence suggests they generally do not increase PA outside of school-time; which may be one reason why school-based activity interventions yield minimal effects on adiposity [48,49]. Additionally, youth may become more independent in their health decisions as they age into adolescence [50], and evidence 
shows that youth spend a majority of after-school time being sedentary [51]. Establishing healthy habits by finding strategies to increase MVPA outside of school may be a method for reducing body fatness. Our results indicate that interventions that implement 30 min reallocations of ST to LPA or MVPA outside of school-time may potentially be effective in reducing overall body fat in boys.

Our cross-sectional findings suggest that replacing $30 \mathrm{~min} /$ day of LPA with MVPA may relate to lower BMI in boys. This association may be transient because it was not observed longitudinally; the reallocation of activity may influence BMI proximally, rather than over this 30-month period of time. Other studies utilizing isotemporal substitution modeling found cross-sectional and prospective associations between activity replacement and BMI in youth of similar age [52]. Although BMI is frequently used in the literature due to its ease of measurement [53], it may not be the best measure of adiposity, particularly among pubertal youth, as it fails to capture adiposity beyond generalized body proportions and does not capture body fat distribution [54]. Considering that BMI provides a limited scope, our findings regarding $\mathrm{BF} \%$ in boys provide stronger health implications for activity reallocation.

High central adiposity is associated with adverse health outcomes in youth, including increased cardiometabolic risk [9]. We found that among boys, replacing $30 \mathrm{~min} /$ day of LPA with MVPA may relate to lower WHR. Although our finding was marginal, the association of replacing LPA with MVPA on WHR is consistent with the strong evidence that supports a dose-response relationship between PA intensity and abdominal obesity [55]. It has been suggested that higher intensity PA is more effective in triggering the secretion of lipolytic hormones, promoting greater post-PA energy expenditure and fat oxidation, and supporting greater negative energy balance-all aspects that contribute to lower visceral abdominal fat [56]. Future studies should consider analyzing the relationship between reallocating time spent in LPA with MVPA and central adiposity since our study was only able to find a marginally significant association.

Unexpectedly, the isotemporal substitution models suggested that replacing LPA with ST would have favorable effects on BMI, WHR, and BF\% in boys cross-sectionally. These findings were marginal and could be an artifact of the statistical analyses that were performed. Opposingly, other studies using isotemporal models found that replacing ST with LPA was related with improved adiposity, including lower waist circumference, WHR, fat mass, and BMI $[16,18,52]$. Our marginally significant findings counteract the traditional thought that any type of PA is better than ST, and these contradictory findings may be attributed to the possibility that only certain types of ST are related to adiposity $[57,58]$. Previous studies found that sedentary behaviors such as screen-time and television watching were associated with higher adiposity, whereas homework and reading were not $[57,58]$. The type of ST, which is not captured by accelerometers, may be an important explanatory factor, therefore future studies should consider gathering the type of ST using validated self-report measures to distinguish possible contextual differences.

Interestingly, we only found associations between activity reallocation and adiposity outcomes in boys. This could be because adiposity changes among girls in this age group may not be entirely attributable to changes in PA and ST, rather they could be due to changes in growth, development, and puberty-related hormones [59]. Anthropometric studies indicate that sex-specific patterning of fat emerges during puberty, suggesting that girls tend to carry less fat around the waist but more around the hips compared to boys $[60,61]$. Studies using direct measures of body fat demonstrated that girls have more fat than boys prior to the onset of puberty $[25,26]$. Higher body fat prior to puberty combined with decreases in PA and increases in ST in girls of this age may indicate that girls need larger amounts of time in PA than in ST compared to boys. Therefore, girls in this age group during this time may require more than $30 \mathrm{~min} /$ day in behavioral changes, or even a multifaceted approach that targets multiple activity behaviors and diet, to elicit favorable changes in body fat. 
A strength of our study is that it captures youth during a unique developmental period in their life. During the 30 months of follow-up for this age, youth were undergoing the transition through puberty and had decreases in PA and increases in ST [38]. Non-school time PA and ST were measured via accelerometry, which provided objective measures of body movement. We used isotemporal substitution models to provide mathematical estimations of reallocation associations of ST, LPA, and MVPA outside of school-time on adiposity. We focused on non-school time activity because it is understudied and more likely to be under the youth's control. Furthermore, this study contributes to the literature by showing that activity reallocation can potentially benefit adiposity in boys.

This study also has limitations. Although our models yielded sufficient statistical power, thus it is possible that some of the models were underpowered given the small sample size. Sample size calculations suggested we needed 62-72 participants and some of our analyses only had 57-65 participants. This also may have contributed to our higher number of marginally significant compared to significant findings. A known limitation of the isotemporal substitution models is multicollinearity given the number of activity variables that are entered into the models [15]. The highest correlation in our study was between ST and total wear-time $(r=0.89)$, which was expected considering that ST made up most of the total wear-time. However, there was relatively little intercorrelation between the other activity variables ( $r$ ranging from $0.01-0.74)$. Although we collected self-reported puberty data, we opted not to control for puberty due to the large amount of missing data ( $n=38$ missing at baseline; $n=36$ missing at follow-up). Puberty is important for fat accumulation [62] and therefore should be measured and included in isotemporal substitution models in future studies. There were additional covariates (e.g., dietary intake, sleep) not controlled for in our analyses known to influence adiposity that future studies may want to explore [63]. We were unable to establish causality due to the observational nature of this study. Furthermore, accelerometry does not capture activities such as biking, upper-arm movements, and swimming, so it is possible there were activities unaccounted for [64]. Lastly, we were unable to distinguish the mode of sedentary and physical activities participated in; future studies should consider gathering the context and type of activity to provide more insight for interventions.

\section{Conclusions}

This study found that reallocating $30 \mathrm{~min} /$ day of non-school time LPA to MVPA and ST to MVPA was cross-sectionally related to lower $\mathrm{BF} \%$ in boys; longitudinal associations were marginal. We additionally found marginal cross-sectional associations between replacing $30 \mathrm{~min} /$ day of non-school time LPA with MVPA and WHR and BMI in boys. However, our study was unable to demonstrate reallocation associations in girls, suggesting that fat accumulation in girls may be a result of a combination of other factors that are not yet understood. As our study focused on non-school time activity behaviors during the critical pubertal transition, it offers insight into sex-specific targeted intervention strategies. Future interventions in boys should consider targeting non-school time activity displacement for the purposes of adiposity control, which could therefore counteract the adverse consequences of high childhood adiposity. Future studies in girls should consider using a multi-behavioral approach, as it appears that activity outside of school-time may not be the driving factor in adiposity status.

Supplementary Materials: The following are available online at https:/ /www.mdpi.com/article/10 .3390 /ijerph18094671/s1, Table S1a: Cross-sectional replacement effects ( $\beta$ [95\% CI]) at follow-up of substituting 15 min of non-school time LPA, MVPA, and ST on BMI, WHR, and BF\% in boys, Table S1b: Cross-sectional replacement effects $(\beta[95 \% \mathrm{CI}])$ at follow-up of substituting 15 min of nonschool time LPA, MVPA, and ST on BMI, WHR, and BF\% in girls, Table S1c: Isotemporal substitution associations ( $\beta[95 \% \mathrm{CI}]$ ) between 15-month changes in non-school time LPA, MVPA, and ST and $\mathrm{BMI}, \mathrm{WHR}$, and $\mathrm{BF} \%$ at 30-month follow-up in boys, Table S1d: Isotemporal substitution associations ( $\beta[95 \% \mathrm{CI}]$ ) between 15-month changes in non-school time LPA, MVPA, and ST and BMI, WHR, and $\mathrm{BF} \%$ at 30 -month follow-up in girls. 
Author Contributions: Conceptualization, K.L.M., J.Z. and B.R.B.; methodology, K.L.M., J.Z., D.C., B.R.B. and G.F.D.; formal analysis, K.L.M.; project administration, G.F.D.; data curation, D.C.; writingoriginal draft preparation, K.L.M.; writing-review and editing, K.L.M., J.Z., B.R.B. and G.F.D.; supervision, B.R.B. and G.F.D.; funding acquisition, G.F.D. All authors have read and agreed to the published version of the manuscript.

Funding: This study was funded by the National Heart, Lung, and Blood Institute (R01HL119255). B.R.B. was funded by the National Institute of Diabetes and Digestive and Kidney Diseases (K01DK113062) and the University of Southern California Office of the Provost. K.L.M. was funded by the University of Southern California Graduate School Provost. J.Z. was funded by the National Cancer Institute (T32CA009492).

Data Availability Statement: The data used to support the findings in this study are available from the corresponding author upon request.

Acknowledgments: We thank Amy Nguyen (Department of Preventive Medicine, University of Southern California) for her large contribution to data collection and management. We thank the study participants for taking the time and effort to participate in this study.

Conflicts of Interest: The authors declare no conflict of interest.

Ethical Statement: Informed consent was obtained from all subjects involved in the study. The study was conducted according to the guidelines of the Declaration of Helsinki and approved by the Institutional Review Board of the University of Southern California (HS-12-00446).

\section{References}

1. Hales, C.M.; Carroll, M.D.; Fryar, C.D.; Ogden, C.L. Prevalence of Obesity among Adults and Youth: United States, 2015-2016; NCHS Data Brief; National Center for Health Statistics: Hyattsville, MD, USA, 2017.

2. Velasquez-Mieyer, P.; Perez-Faustinelli, S.; Cowan, P.A. Identifying children at risk for obesity, type 2 diabetes, and cardiovascular disease. Diabetes Spectr. 2005, 18, 213-220. [CrossRef]

3. Simmonds, M.; Llewellyn, A.; Owen, C.G.; Woolacott, N. Predicting adult obesity from childhood obesity: A systematic review and meta-analysis. Obes. Rev. 2016, 17, 95-107. [CrossRef]

4. Rundle, A.G.; Factor-Litvak, P.; Suglia, S.F.; Susser, E.S.; Kezios, K.L.; Lovasi, G.S.; Cirillo, P.M.; Cohn, B.A.; Link, B.G. Tracking of Obesity in Childhood into Adulthood: Effects on Body Mass Index and Fat Mass Index at Age 50. Child. Obes. 2020, 16, 226-233. [CrossRef] [PubMed]

5. Deshmukh-Taskar, P.; Nicklas, T.A.; Morales, M.; Yang, S.J.; Zakeri, I.; Berenson, G.S. Tracking of overweight status from childhood to young adulthood: The Bogalusa Heart Study. Eur. J. Clin. Nutr. 2006, 60, 48-57. [CrossRef]

6. Herman, K.M.; Craig, C.L.; Gauvin, L.; Katzmarzyk, P.T. Tracking of obesity and physical activity from childhood to adulthood: The Physical Activity Longitudinal Study. Int. J. Pediatr. Obes. 2009, 4, 281-288. [CrossRef]

7. Maffeis, C.; Moghetti, P.; Grezzani, A.; Clementi, M.; Gaudino, R.; Tato, L. Insulin resistance and the persistence of obesity from childhood into adulthood. J. Clin. Endocrinol. Metab. 2002, 87, 71-76. [CrossRef] [PubMed]

8. Katzmarzyk, P.T.; Srinivasan, S.R.; Chen, W.; Malina, R.M.; Bouchard, C.; Berenson, G.S. Body mass index, waist circumference, and clustering of cardiovascular disease risk factors in a biracial sample of children and adolescents. Pediatrics 2004, 114, e198-e205. [CrossRef] [PubMed]

9. Kelishadi, R.; Mirmoghtadaee, P.; Najafi, H.; Keikha, M. Systematic review on the association of abdominal obesity in children and adolescents with cardio-metabolic risk factors. J. Res. Med. Sci. 2015, 20, 294-307. [PubMed]

10. Janz, K.F.; Boros, P.; Letuchy, E.M.; Kwon, S.; Burns, T.L.; Levy, S.M. Physical Activity, Not Sedentary Time, Predicts Dual-Energy X-ray Absorptiometry-measured Adiposity Age 5 to 19 Years. Med. Sci. Sports. Exerc. 2017, 49, 2071-2077. [CrossRef]

11. Jenkins, G.P.; Evenson, K.R.; Herring, A.H.; Hales, D.; Stevens, J. Cardiometabolic Correlates of Physical Activity and Sedentary Patterns in U.S. Youth. Med. Sci. Sports Exerc. 2017, 49, 1826-1833. [CrossRef]

12. Dowd, K.P.; Harrington, D.M.; Hannigan, A.; Donnelly, A.E. Light-intensity physical activity is associated with adiposity in adolescent females. Med. Sci. Sports Exerc. 2014, 46, 2295-2300. [CrossRef] [PubMed]

13. Norman, G.J.; Carlson, J.A.; Patrick, K.; Kolodziejczyk, J.K.; Godino, J.G.; Huang, J.; Thyfault, J. Sedentary Behavior and Cardiometabolic Health Associations in Obese 11-13-Year Olds. Child. Obes. 2017, 13, 425-432. [CrossRef]

14. Wijndaele, K.; White, T.; Andersen, L.B.; Bugge, A.; Kolle, E.; Northstone, K.; Wedderkopp, N.; Ried-Larsen, M.; Kriemler, S.; Page, A.S.; et al. Substituting prolonged sedentary time and cardiovascular risk in children and youth: A meta-analysis within the International Children's Accelerometry database (ICAD). Int. J. Behav. Nutr. Phys. Act. 2019, 16, 96. [CrossRef] [PubMed]

15. Mekary, R.A.; Willett, W.C.; Hu, F.B.; Ding, E.L. Isotemporal substitution paradigm for physical activity epidemiology and weight change. Am. J. Epidemiol. 2009, 170, 519-527. [CrossRef] 
16. Fairclough, S.J.; Dumuid, D.; Taylor, S.; Curry, W.; McGrane, B.; Stratton, G.; Maher, C.; Olds, T. Fitness, fatness and the reallocation of time between children's daily movement behaviours: An analysis of compositional data. Int. J. Behav. Nutr. Phys. Act. 2017, 14, 64. [CrossRef] [PubMed]

17. Loprinzi, P.D.; Cardinal, B.J.; Lee, H.; Tudor-Locke, C. Markers of adiposity among children and adolescents: Implications of the isotemporal substitution paradigm with sedentary behavior and physical activity patterns. J. Diabetes Metab. Disord. 2015, 14, 46. [CrossRef] [PubMed]

18. Sardinha, L.B.; Marques, A.; Minderico, C.; Ekelund, U. Cross-sectional and prospective impact of reallocating sedentary time to physical activity on children's body composition. Pediatr. Obes. 2017, 12, 373-379. [CrossRef]

19. Dumuid, D.; Stanford, T.E.; Pedisic, Z.; Maher, C.; Lewis, L.K.; Martin-Fernandez, J.A.; Katzmarzyk, P.T.; Chaput, J.P.; Fogelholm, M.; Standage, M.; et al. Adiposity and the isotemporal substitution of physical activity, sedentary time and sleep among school-aged children: A compositional data analysis approach. BMC Public Health 2018, 18, 311. [CrossRef]

20. Grao-Cruces, A.; Velasquez-Romero, M.J.; Rodriguez-Rodriguez, F. Levels of Physical Activity during School Hours in Children and Adolescents: A Systematic Review. Int. J. Environ. Res. Public Health 2020, 4773. [CrossRef]

21. Hubbard, K.; Economos, C.D.; Bakun, P.; Boulos, R.; Chui, K.; Mueller, M.P.; Smith, K.; Sacheck, J. Disparities in moderateto-vigorous physical activity among girls and overweight and obese schoolchildren during school- and out-of-school time. Int. J. Behav. Nutr. Phys. Act. 2016, 13, 39. [CrossRef]

22. Galloway, R.; Booker, R.; Owens, S. Factors leading to discrepancies in accumulated physical activity during school hours in elementary school students. J. Teach. Phys. Educ. 2019, 38, 338-346. [CrossRef]

23. Dale, D.; Corbin, C.B.; Dale, K.S. Restricting opportunities to be active during school time: Do children compensate by increasing physical activity levels after school? Res. Q. Exerc. Sport 2000, 71, 240-248. [CrossRef] [PubMed]

24. Nyberg, G.A.; Nordenfelt, A.M.; Ekelund, U.; Marcus, C. Physical activity patterns measured by accelerometry in 6- to 10-yr-old children. Med. Sci. Sports Exerc. 2009, 41, 1842-1848. [CrossRef]

25. Dencker, M.; Thorsson, O.; Linden, C.; Wollmer, P.; Andersen, L.B.; Karlsson, M.K. BMI and objectively measured body fat and body fat distribution in prepubertal children. Clin. Physiol. Funct. Imaging 2007, 27, 12-16. [CrossRef]

26. He, Q.; Horlick, M.; Thornton, J.; Wang, J.; Pierson, R.N., Jr.; Heshka, S.; Gallagher, D. Sex and race differences in fat distribution among Asian, African-American, and Caucasian prepubertal children. J. Clin. Endocrinol. Metab. 2002, 87, 2164-2170. [CrossRef]

27. Staiano, A.E.; Katzmarzyk, P.T. Ethnic and sex differences in body fat and visceral and subcutaneous adiposity in children and adolescents. Int. J. Obes. 2012, 36, 1261-1269. [CrossRef]

28. Dunton, G.F.; Liao, Y.; Dzubur, E.; Leventhal, A.M.; Huh, J.; Gruenewald, T.; Margolin, G.; Koprowski, C.; Tate, E.; Intille, S Investigating within-day and longitudinal effects of maternal stress on children's physical activity, dietary intake, and body composition: Protocol for the MATCH study. Contemp Clin Trials 2015, 43, 142-154. [CrossRef] [PubMed]

29. Rundle, A.; Richards, C.; Bader, M.D.; Schwartz-Soicher, O.; Lee, K.K.; Quinn, J.; Lovasi, G.S.; Weiss, C.; Neckerman, K. Individualand school-level sociodemographic predictors of obesity among New York City public school children. Am. J. Epidemiol. 2012, 176, 986-994. [CrossRef]

30. Guerrero, A.D.; Flores, M.; Vangala, S.; Chung, P.J. Differences in the Association of Physical Activity and Children's Overweight and Obesity Status Among the Major Racial and Ethnic Groups of U.S. Children. Health Educ. Behav. 2017, 44, 411-420. [CrossRef] [PubMed]

31. National Health and Nutrition Examination Survey. Anthropometry Procedures Manual. Available online: https://www.cdc. gov/nchs/data/nhanes/nhanes_07_08/manual_an.pdf (accessed on 21 March 2020).

32. Hosking, J.; Metcalf, B.S.; Jeffery, A.N.; Voss, L.D.; Wilkin, T.J. Validation of foot-to-foot bioelectrical impedance analysis with dual-energy X-ray absorptiometry in the assessment of body composition in young children: The EarlyBird cohort. Br. J. Nutr. 2006, 96, 1163-1168. [CrossRef]

33. Lee, L.W.; Liao, Y.S.; Lu, H.K.; Hsiao, P.L.; Chen, Y.Y.; Chi, C.C.; Hsieh, K.C. Validation of two portable bioelectrical impedance analyses for the assessment of body composition in school age children. PLoS ONE 2017, 12, e0171568. [CrossRef]

34. Belcher, B.R.; Berrigan, D.; Dodd, K.W.; Emken, B.A.; Chou, C.P.; Spruijt-Metz, D. Physical activity in US youth: Effect of race/ethnicity, age, gender, and weight status. Med. Sci. Sports Exerc. 2010, 42, 2211-2221. [CrossRef] [PubMed]

35. Matthews, C.E.; Chen, K.Y.; Freedson, P.S.; Buchowski, M.S.; Beech, B.M.; Pate, R.R.; Troiano, R.P. Amount of time spent in sedentary behaviors in the United States, 2003-2004. Am. J. Epidemiol. 2008, 167, 875-881. [CrossRef] [PubMed]

36. Troiano, R.P.; Berrigan, D.; Dodd, K.W.; Masse, L.C.; Tilert, T.; McDowell, M. Physical activity in the United States measured by accelerometer. Med. Sci. Sports Exerc. 2008, 40, 181-188. [CrossRef]

37. Toftager, M.; Kristensen, P.L.; Oliver, M.; Duncan, S.; Christiansen, L.B.; Boyle, E.; Brond, J.C.; Troelsen, J. Accelerometer data reduction in adolescents: Effects on sample retention and bias. Int. J. Behav. Nutr. Phys. Act. 2013, 10, 140. [CrossRef]

38. Dunton, G.F.; Yang, C.H.; Zink, J.; Dzubur, E.; Belcher, B.R. Longitudinal Changes in Children's Accelerometer-derived Activity Pattern Metrics. Med. Sci. Sports Exerc. 2020, 52, 1307-1313. [CrossRef]

39. Freedson, P.; Pober, D.; Janz, K.F. Calibration of accelerometer output for children. Med. Sci. Sports Exerc. 2005, 37, S523-S530. [CrossRef]

40. Treuth, M.S.; Schmitz, K.; Catellier, D.J.; McMurray, R.G.; Murray, D.M.; Almeida, M.J.; Going, S.; Norman, J.E.; Pate, R. Defining accelerometer thresholds for activity intensities in adolescent girls. Med. Sci. Sports Exerc. 2004, 36, 1259-1266. [PubMed] 
41. Jones, M.A.; Skidmore, P.M.; Stoner, L.; Harrex, H.; Saeedi, P.; Black, K.; Barone Gibbs, B. Associations of accelerometer-measured sedentary time, sedentary bouts, and physical activity with adiposity and fitness in children. J. Sports Sci. 2020, 38, 114-120. [CrossRef]

42. Faul, F.; Erdfelder, E.; Buchner, A.; Lang, A.G. Statistical power analyses using G*Power 3.1: Tests for correlation and regression analyses. Behav. Res. Methods 2009, 41, 1149-1160. [CrossRef] [PubMed]

43. Bailey, T.; Bode, B.W.; Christiansen, M.P.; Klaff, L.J.; Alva, S. The Performance and Usability of a Factory-Calibrated Flash Glucose Monitoring System. Diabetes Technol. 2015, 17, 787-794. [CrossRef] [PubMed]

44. Dalene, K.E.; Anderssen, S.A.; Andersen, L.B.; Steene-Johannessen, J.; Ekelund, U.; Hansen, B.H.; Kolle, E. Secular and longitudinal physical activity changes in population-based samples of children and adolescents. Scand. J. Med. Sci. Sports 2018, 28, 161-171. [CrossRef]

45. Harding, S.K.; Page, A.S.; Falconer, C.; Cooper, A.R. Longitudinal changes in sedentary time and physical activity during adolescence. Int. J. Behav. Nutr. Phys. Act. 2015, 12, 44. [CrossRef] [PubMed]

46. Cameron, C.; Craig, C.L.; Bauman, A.; Tudor-Locke, C. CANPLAY study: Secular trends in steps/day amongst 5-19year-old Canadians between 2005 and 2014. Prev. Med. 2016, 86, 28-33. [CrossRef]

47. Collings, P.J.; Westgate, K.; Vaisto, J.; Wijndaele, K.; Atkin, A.J.; Haapala, E.A.; Lintu, N.; Laitinen, T.; Ekelund, U.; Brage, S.; et al. Cross-Sectional Associations of Objectively-Measured Physical Activity and Sedentary Time with Body Composition and Cardiorespiratory Fitness in Mid-Childhood: The PANIC Study. Sports Med. 2017, 47, 769-780. [CrossRef] [PubMed]

48. Errisuriz, V.L.; Golaszewski, N.M.; Born, K.; Bartholomew, J.B. Systematic Review of Physical Education-Based Physical Activity Interventions Among Elementary School Children. J. Prim. Prev. 2018, 39, 303-327. [CrossRef]

49. Kain, J.; Concha, F.; Moreno, L.; Leyton, B. School-based obesity prevention intervention in Chilean children: Effective in controlling, but not reducing obesity. J. Obes. 2014, 2014, 618293. [CrossRef]

50. He, K.; Kramer, E.; Houser, R.F.; Chomitz, V.R.; Hacker, K.A. Defining and understanding healthy lifestyles choices for adolescents. J. Adolesc. Health 2004, 35, 26-33. [CrossRef]

51. Arundell, L.; Hinkley, T.; Veitch, J.; Salmon, J. Contribution of the After-School Period to Children's Daily Participation in Physical Activity and Sedentary Behaviours. PLoS ONE 2015, 10, e0140132. [CrossRef]

52. Dalene, K.E.; Anderssen, S.A.; Andersen, L.B.; Steene-Johannessen, J.; Ekelund, U.; Hansen, B.H.; Kolle, E. Cross-sectional and prospective associations between physical activity, body mass index and waist circumference in children and adolescents. Obes. Sci. Pract. 2017, 3, 249-257. [CrossRef]

53. Hall, D.M.; Cole, T.J. What use is the BMI? Arch. Dis. Child. 2006, 91, 283-286. [CrossRef] [PubMed]

54. Daniels, S.R. The use of BMI in the clinical setting. Pediatrics 2009, 124 (Suppl. 1), S35-S41. [CrossRef]

55. Hay, J.; Maximova, K.; Durksen, A.; Carson, V.; Rinaldi, R.L.; Torrance, B.; Ball, G.D.; Majumdar, S.R.; Plotnikoff, R.C.; Veugelers, P.; et al. Physical activity intensity and cardiometabolic risk in youth. Arch. Pediatr. Adolesc. Med. 2012, 166, 1022-1029. [CrossRef] [PubMed]

56. Irving, B.A.; Davis, C.K.; Brock, D.W.; Weltman, J.Y.; Swift, D.; Barrett, E.J.; Gaesser, G.A.; Weltman, A. Effect of exercise training intensity on abdominal visceral fat and body composition. Med. Sci. Sports Exerc. 2008, 40, 1863-1872. [CrossRef]

57. Sisson, S.B.; Broyles, S.T.; Baker, B.L.; Katzmarzyk, P.T. Television, reading, and computer time: Correlates of school-day leisuretime sedentary behavior and relationship with overweight in children in the U.S. J. Phys. Act. Health 2011, 8 (Suppl. 2), S188-S197. [CrossRef]

58. Coombs, N.A.; Stamatakis, E. Associations between objectively assessed and questionnaire-based sedentary behaviour with BMI-defined obesity among general population children and adolescents living in England. BMJ Open 2015, 5, e007172. [CrossRef]

59. Mihalopoulos, N.L.; Holubkov, R.; Young, P.; Dai, S.; Labarthe, D.R. Expected changes in clinical measures of adiposity during puberty. J. Adolesc. Health 2010, 47, 360-366. [CrossRef]

60. Heude, B.; Kettaneh, A.; de Lauzon Guillain, B.; Lommez, A.; Borys, J.M.; Ducimetiere, P.; Charles, M.A.; Fleurbaix Laventie Ville Santé Group. Growth curves of anthropometric indices in a general population of French children and comparison with reference data. Eur. J. Clin. Nutr. 2006, 60, 1430-1436. [CrossRef]

61. Malina, R.M. Regional body composition: Age, sex, and ethnic variation. In Human Body Composition; Roche, A.F., Heymsfield, S.B., Lohman, T.G., Eds.; Human Kinetics: Champaign, IL, USA, 1996.

62. Siervogel, R.M.; Demerath, E.W.; Schubert, C.; Remsberg, K.E.; Chumlea, W.C.; Sun, S.; Czerwinski, S.A.; Towne, B. Puberty and body composition. Horm. Res. 2003, 60, 36-45. [CrossRef]

63. Chaput, J.P.; Gray, C.E.; Poitras, V.J.; Carson, V.; Gruber, R.; Olds, T.; Weiss, S.K.; Connor Gorber, S.; Kho, M.E.; Sampson, M.; et al. Systematic review of the relationships between sleep duration and health indicators in school-aged children and youth. Appl. Physiol. Nutr. Metab. 2016, 41, S266-S282. [CrossRef]

64. Spruijt-Metz, D.; Berrigan, D.; Kelly, L.A. Measures of physical activity and exercise. In Handbook of Assessment Methods for Eating Behaviors and Weight-Related Problems: Measures, Theory, and Research; Sage Publications: Thousand Oaks, CA, USA, 2009. 